\title{
Teledermatology consulting centre Which rural area is suitable?
}

\author{
Shrestha $\mathrm{S}^{1}$, Jha $\mathrm{AK}^{2}$ \\ ${ }^{1}$ Lecturer, ${ }^{2}$ Professor and Head, \\ Department of Dermatology, Venereology \& Leprology, \\ Nepal Medical College and Teaching Hospital, \\ Attarkhel, Jorpati, \\ Kathmandu, Nepal. \\ Correspondence: Dr. Shristi Shrestha, \\ Email: sonyjony@gmail.com
}

\begin{abstract}
Background: Teledermatology is an upcoming branch of Telemedicine which is in infant stage in our country Nepal. Nepal is a developing mountainous and hilly country with a large number of rural areas with minimal and difficult transport means. Besides due to paucity of specialist doctors in a country like ours populations from rural areas have minimal access to specialist care. So, development of Teledermatology focusing such areas will give maximum benefit to the patients with minimal expense.

Objective: As Nepal Medical College and Teaching Hospital is in the process of becoming a specialty centre for Teledermatology programme in near future the primary requirement is to find out among the patients visiting our outpatient department who would benefit from this service.

Method: A retrospective study is conducted to find out the district (rural area) from where maximum numbers of patients visit our outpatient department on daily basis to start a Teledermatology consulting centre there.

Findings: Within Bagmati zone maximum patients were from Kathmandu district, second was Sindhupalchowk district $(9 \%)$.

Conclusion: Since the primary goal of starting Teledermatology service in a developing country like ours is to serve the underserved population, opening a teleconsultation centre in a rural area like Sindhupalchowk would serve our goal. At the same time we have to see how this programme ean be made sustainable in future.

Keywords: Telemedicine, Teledermatology, Nepal, Sindhupalchowk, Teleconsulting centre, rural areas.
\end{abstract}

\section{Introduction}

"Tele" in Greek means "distance" and "mederi" in Latin means "to heal".

Telemedicine is defined by the WHO as ' the practice of healthcare using interactive audio, visual and data communications which includes health care delivery, diagnoses, consultation and treatment as well as education and transfer of medical data. ${ }^{2}$ Telemedicine could play a major role in changing the way healthcare and healthrelated information are accessed and delivered in developing and underdeveloped areas that have poor physical facilities for communication and transport and limited numbers of medical facilities. ${ }^{3}$ Teledermatology is the delivery of dermatologic patient care through telemedicine technologies. The goal is to provide the highest quality of dermatologic care more efficiently by moving patient information rather than the patient.

1. Our country Nepal is a country with geographic diversity with lots of hilly and mountainous regions which makes communication and transport difficult.

2. Being a developing country maximum population is of low socio-economic status.
3. Number of specialist doctors is less and they are mostly confined to urban regions due to which rural population is deprived of specialist care.

Focusing at these factors, starting Teledermatology practice could be a good solution for these problems.

Nepal Medical College and Teaching Hospital along with an organization named Community Health Education Services by Telehealth (C.H.E.S.T) is in the process of starting Teledermatology service in near future. As our main aim is to provide benefits to the rural communities with minimal expense, before starting this service we thought it is our duty to find out which rural area will benefit from this service in context with our outpatient department. So this retrospective study is done to find out the rural area (district) from where maximum numbers of patients visit our outpatient department on daily basis so that we could consider this area for a Teledermatology consulting centre. 
Material and Methods

A retrospective study was done of all the patients visiting the Department of Dermatology, Venereology \& Leprology outpatient department at Nepal Medical College and Teaching Hospital from 1st Baisakh 2064 (14 ${ }^{\text {th }}$ April 2007) to 30th Chaitra 2064(12 $2^{\text {th }}$ April 2008). The address of the patients were noted and categorized according to the zones/districts.

\section{Results}

In total there were 11,944 patients. There were patients from all the 14 zones which is shown in Fig 1 and Table 1 . Out of 75 districts patients were present from 65 districts. Maximum numbers of patients were from the Bagmati zone (91.2\%) the reason being very obvious. Within Bagmati zone maximum patients were from the Kathmandu district (83.9\%) (Fig and Table 2). The second largest numbers of patients were from the Sindhupalchowk district $(8.87 \%)$ which is $85 \mathrm{~km}$ away to the north east of Kathmandu valley and is one of the least developed districts of Nepal.

\section{Discussion}

Telecommunications and information technology is showing rapid development these days. It is high time we use these in order to revolutionize the delivery of health care. Teledermatology is an upcoming branch in dermatology which has been started in many countries. It can be (i) Real time or video conference Teledermatology (VCTD) (ii) Store and forward (SAF) system (iii) Hybrid. The goals of Teledermatology are to reach out to people residing in undeserved areas, to decrease the costs and time consumption of providing some health services and to improve the quality of care. ${ }^{5}$ Armstrong et al in a study comparing the cost of operating an interactive teledermatology practice in a remote region with that of a conventional clinic in a nearby urban centre found that from a healthcare provider perspective, interactive Teledermatology can be economically viable means of providing dermatological care to remote regions. ${ }^{6}$ Loane et al found that in urban areas the average costs of the telemedicine and conventional consultations were about equal, while in rural areas the average cost of the telemedicine consultation was less than that of the conventional consultation. ${ }^{7}$ Taking account of our study the maximum number of patients are from Kathmandu district. But considering the primary aim of starting Teledermatology which is to serve undeserved populations this place doesn't serve well. So Sindhupalchowk being the second in the list and as Sindhupalchowk is a rural village with large population of low socio-economic status, making our teleconsultation centre there would be very helpful in fulfilling our aim.

Several studies conducted in different parts of the world have showed high satisfaction rates with Teledermatology services on both the patient and physician sides. ${ }^{8,9,10,11,12,13,14,15,16,17}$ Studies have been done even in some particular fields of dermatology. In a survey among Pediatric dermatologists it was noted that Teledermatology allows more accurate triage of dermatology patients, decreases travel and outpatient clinic visits and provides an avenue for ongoing support and education for primary care physicians. ${ }^{18}$ In another study comparing the accuracy of diagnosis made by telemedicine with that made by in-person examination in suspected cases of leprosy, it was found that Teledermatology increases the speed of diagnosis for leprosy and reduce the development of disabilities. ${ }^{19}$ Hence it could help in leprosy control programmes. Teledermatology was found helpful in rapid evaluation, successful assessment and treatment of hard to heal ulcers with minimal cost. ${ }^{20,21}$ In pigmented skin lesions and skin neoplasm also teleconsultation has been found to be helpful in triage of patients.

\section{Conclusion}

Though many studies conducted in different parts of the world show exciting and encouraging results, we ourselves should conduct studies in future considering the diagnostic reliability, management reliability, cost effectiveness, patient and practitioner satisfaction, etc. An import challenge for us is the sustainability of this service in years to come. Therefore as a means of health service delivery, Teledermatology has to be planned and operated appropriately to provide acceptable and sustainable support to rural communities like Sindhupalchowk district especially in a country like Nepal where skin diseases are very much prevalent.

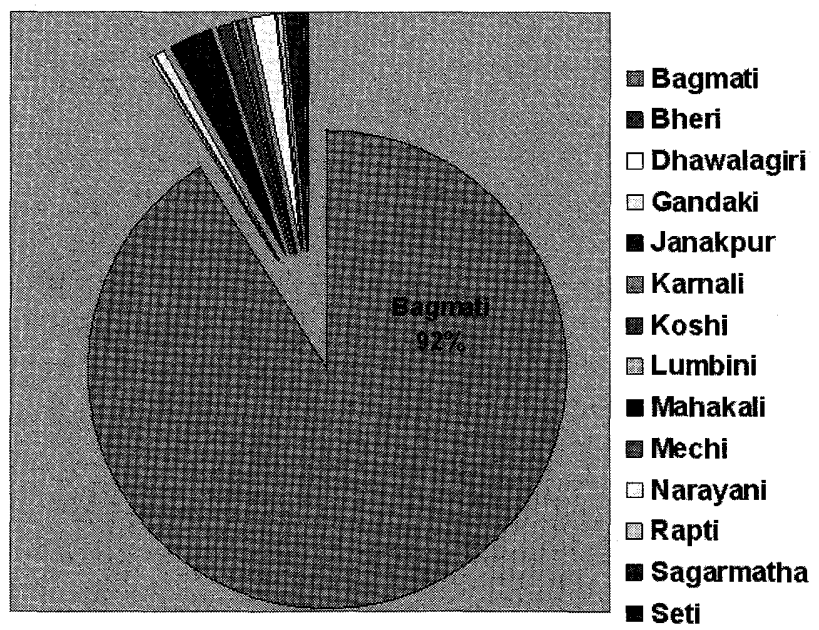

Figure 1: Distribution of patients according to zones. 
Table 1. Distribution of patients according to zones.

\begin{tabular}{|l|l|l|l|}
\hline S. no & Zones & No. of patients & Percentage \\
\hline 1. & Bagmati & 10890 & $91.2 \%$ \\
\hline 2. & Bheri & 4 & $0.03 \%$ \\
\hline 3. & Dhawalagiri & 18 & $0.15 \%$ \\
\hline 4. & Gandaki & 70 & $0.6 \%$ \\
\hline 5. & Janakpur & 353 & $2.95 \%$ \\
\hline 6. & Karnali & 10 & $0.08 \%$ \\
\hline 7. & Koshi & 85 & $0.7 \%$ \\
\hline 8. & Lumbini & 55 & $0.5 \%$ \\
\hline 9. & Mahakali & 4 & $0.03 \%$ \\
\hline 10. & Mechi & 54 & $0.45 \%$ \\
\hline 11. & Narayani & 195 & $1.63 \%$ \\
\hline 12. & Rapti & 39 & $0.3 \%$ \\
\hline 13. & Sagarmatha & 147 & $1.23 \%$ \\
\hline 14. & Seti & 20 & $0.17 \%$ \\
\hline
\end{tabular}

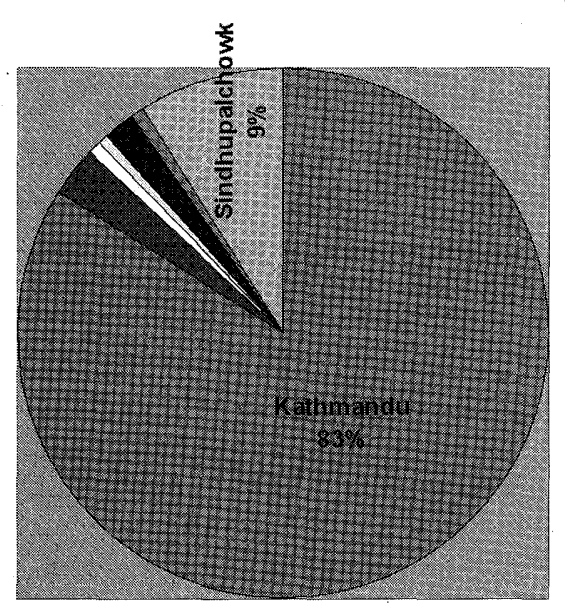

\begin{tabular}{|l|}
\hline Kathmandu \\
B Bhaktapur \\
$\square$ Dhading \\
$\square$ Kavrepalanchowk \\
Lalitpur \\
Nuwakot \\
Nasuwa \\
R Sindhupalchowk \\
\hline
\end{tabular}

Figure 2. Distribution of patients according to districts within Bagmati zone.

\begin{tabular}{|l|l|l|l|}
\hline S. no & Districts & No. of patients & Percentage \\
\hline 1. & Bhaktapur & 332 & $3 \%$ \\
\hline 2. & Dhading & 77 & $0.7 \%$ \\
\hline 3. & Kathmandu & 9142 & $83.9 \%$ \\
\hline 4. & Lalitpur & 234 & $2.1 \%$ \\
\hline 5. & Nuwakot & 74 & $0.7 \%$ \\
\hline 6. & Rasuwa & 4 & $0.04 \%$ \\
\hline 7. & Sindhupalchowk & 966 & $9 \%$ \\
\hline 8. & Kavrepalanchowk & 61 & $0.56 \%$ \\
\hline
\end{tabular}

Table 2. Distribution of patients according to districts within Bagmati Zone.

\section{References:}

1. Gupta AD, Deb S. Telemedicine: A new horizon in Public health in India. Indian Journal of Community Medicine.2008;33(1):3-8

2. Burg G (ed): Telemedicine and teledermatology. Curr Prob1 Dermatol. Basel, Karger, 2003, vol 32, pp 2.

3. D Hailey. Technology and managed care: Is telemedicine the right tool for rural communities? Journal of Postgraduate medicine. 2005;51:4:275-278

4. Pak HS. Teledermatology \& teledermatopathology. Semin Cut Med Surg 2002;21:179-189.

5. Pamela S. Whitten. Teledermatology Delivery Modalities: Real time versus Store and Forward. Burg G (ed): Telemedicine and teledermatology. Curr Probl
Dermatol. Basel, Karger, 2003, vol 32: pg 24

6. Armstrong A W, Dorer DJ, Lugn NE, Kvedar JC. Economic evaluation of interactive dermatology compared with conventional care. Telemed J E Health. 2007 Apr;13(2):91-9.

7. Loane MA, Bloomer SE, Corbett R, Eedy DJ, Evans C, Hicks $\mathrm{N}$, et al. A randomized controlled trial assessing the health economics of realtime Teledermatology compared with conventional care: An urban versus rural perspective. J Telemed Telecare. 2001;7:108-18

8. Williams T, May C, Esmail A, Ellis N, Griffiths C, Stewart E, et al . Patient satisfaction with store-andforward teledermatology. J Telemed Telecare 2001;7:S456.

9. Weinstock MA, Nguyen FQ, Risica PM. Patient and referring provider satisfaction with teledermatology. J Am Acad Dermatol 2002;47:68-72.

10. Hicks LL, Boles KE, Hudson S, Kling B, Tracy J, Mitchell J, et al . Patient satisfaction with teledermatology services. J Telemed Telecare 2003;9:42-5.E

11. Perednia DA, Wallace J, Morrisey M, Bartlett M, Marchionda L, Gibson A, Campbell E. The effect of a Teledermatology program on rural referral patterns to dermatologists and the management of skin disease. Stud Health Technol. Inform. 1998;52(1):290-3

12. Oakley AM, Kerr P, Duffill M, Rademaker M, Fleischl P, Bradford N, Mills C Patient cost-benefits of realtime Teledermatology - a comparison of data from Northern Ireland and New Zealan. J Telemed Telecare. 2000;6(2):97-101.

13. Loane MA, Bloomer SE, Corbett R, Eedy DJ, Gore HE, Mathews C, Steele K, Wootton R.Patient satisfaction with realtime Teledermatology in Northern Ireland. 1998;4(1):36-40

14. Van den Akker TW, Reker CH, Knol A, Post J, Wilbrink $\mathrm{J}$, van der Veen JP. Teledermatology as a tool for communication between general practitioners and dermatologists. J Telemed Telecare. 2001;7:193-198.

15. Wu YH, Su HY, Hsieh YJ. Survey of infectious skin diseases and skin infestations among primary school students of Taitung County, eastern Taiwan. J Formos Med Assoc. 2000;99:128-134.

16. Kaliyadan F, Venkitakrishnan S. Teledermatology: Clinical case profiles and practical issues. Indian Journ. of Dermat. Venereol. Leprol. 2009;75(!):32-35.

17. Klaz I, Wohl Y, Nathansohn N, Yerushalmi N, Sharvit S, Kochba I, Brenner S. Teledermatology: quality assessment by user satisfaction and clinical efficeincy. Isr Med Assoc J. 2005 Aug;7(8):487-90

18. Fieleke DR, Edison K, Dyer JA. Pediatric Teledermatology - a survey of current use. Pediatr Dermatol. 2008 Mar-Apr;25(2):158-62.

19. Trindade MA, Wen CL, Neto CF, Escuder MM, Andrade VL, Yamashitafuji TM, Manso VL. Accuracy of storeand-forward diagnosis in leprosy. J Telemed Telecare. 2008;14(4):208-10.

20. Chanussot-Deprez C, Contreras-Ruiz J. Telemedicine in wound care. Int Wound J. 2008. Dec;5(5):651-4.

21. Hofmann-Wellenhof R, Salmhofer W, Binder B, Okcu A, Kerl H, Soyer HP. Feasibility and acceptance of telemedicine for wound are in patients with chronic leg ulcers. J Telemed Telecare. 2006;12 Supp1 1:15-17.

22. Moreno-Ramirez D, Ferrandiz L, Galdeano R, Camacho FM. Teledermatoscopy as triage system for pigmented lesions: pilot study. Clin Exp Dermatol. 2006 Jan;31(1):13-8.

23. Shapiro M, James WD, Kessler R, Lazorik FC, Katz KA, Tam J, Nieves DS, Miller JJ. Comparison of skin biopsy triage decisions in 49 patients with pigmented lesions and skin neoplasms: store-and-forward teledermatology vs face-to-face dermatology. Arch of Dermatology;2004 May; 140(5):525-8. 